\title{
Are neonatal morbidities associated with no prenatal care different from those associated with inadequate prenatal care?
}

\author{
Ekwutosi M. Okoroh $^{1}$, Dean V. Coonrod ${ }^{2}$, Kristina Chapple ${ }^{3}$, David Drachman ${ }^{4}$ \\ ${ }^{1}$ Division of Blood Disorders, National Center for Birth Defects and Developmental Disorders, Atlanta, USA \\ ${ }^{2}$ Department of Obstetrics, Gynecology, \& Women's Health, Maricopa Integrated Health System, University of Arizona College of \\ Medicine, Phoenix, USA \\ ${ }^{3}$ Consultant, 9239 E. Desert View, Scottsdale, USA \\ ${ }^{4}$ Department of Research, Maricopa Integrated Health System, Phoenix, USA \\ Email: eokoroh@cdc.gov
}

Received 21 April 2012; revised 20 May 2012; accepted 28 May 2012

\begin{abstract}
Objective: Compare neonatal morbidities in women with no prenatal care, and women with inadequate prenatal care, to those with adequate prenatal care. Methods: Retrospective cohort study of neonatal morbidities of 3 exposure groups. Group 1: No prenatal care; Group 2: Inadequate prenatal care; Group 3: Intermediate/adequate prenatal care. Results: $2.5 \%$, $23.3 \%$ and $74.1 \%$ of subjects $(\mathrm{N}=264,138)$ were in Groups 1, 2 and 3 respectively. Severe neonatal morbidity was more common in Group 1, followed by Group 2, and least common in Group 3. After controlling for gestational age and birth weight, most of these differences were attenuated and not significant except for the following Group 1 vs Group 3 comparisons: meconium aspiration, odds ratio (OR) 2.15 and $95 \%$ confidence interval (CI) 1.39 - 3.33; suspected sepsis, OR 1.30 and CI 1.13 - 1.49; proven viral sepsis, OR 2.23 and CI 1.24 - 4.00. Conclusions: Severe neonatal morbidity was most common in those with no prenatal care followed by those with inadequate prenatal care. For most neonatal morbidities, this could largely be explained by gestational age and birth weight differences, but for some neonatal morbidities (meconium aspirations, viral sepsis and dysmorphic features) the impact of no prenatal care persisted after adjustment for these factors.
\end{abstract}

Keywords: Prenatal Care; Neonatal Outcomes; Retrospective Cohort Study

\section{INTRODUCTION}

According to the most recent estimates, 343,000 mothers died in 2008 from complications related to pregnancy and childbirth [1]. Worldwide, 3.7 million children under 5 die each year, with $40 \%$ of these occurring in the neonatal period [2]. Many more children and mothers suffer ill health and permanent disabilities as a result of complications of pregnancy and childbirth. Credited by some as an American innovation [3], prenatal care is an established mechanism for identifying and managing medical, socio-demographic, and behavioral risk factors that may contribute to poor pregnancy outcomes.

There are 3 main indices (Kessner [4], Kotelchuck [5] and GINDEX [6]) currently used in the literature to measure the adequacy of prenatal care. They vary in definition and limitations. Regardless of how prenatal care is measured, the optimal amount and content of care in low- or high-risk pregnancies is not yet resolved [7]. Furthermore, even when prenatal care is easily accessible and of high quality, some pregnant women choose not to use it. In this study, we used the Kotelchuck Adequacy of Prenatal Care Utilization Index (APNCUI) [5] to characterize prenatal care. This measure incorporates two independent and distinctive dimensions: Adequacy of Initiation of Prenatal Care and Adequacy of Received Services (once prenatal care has begun).

The correlation between neglected prenatal care and an increased rate of maternal and perinatal morbidity has been known since as early as 1914, when Williams reported that timely detection and prompt treatment of pregnancy complications considerably reduced perinatal mortality from a variety of causes, including prematurity [8]. Eastman observed in 1947 a prematurity rate of $24 \%$ among no care patients, but only $8 \%$ among those attending 3 or more prenatal visits [9]. Tokuhata et al. in 1973 studied birth certificate data of 185,000 deliveries and found a $23.6 \%$ prematurity rate among women without prenatal care compared with $6.9 \%$ among those with care [10]. More recently, Debiec et al. in 2010 con- 
ducted a 10 year retrospective study in which they assessed the risk of preterm birth among adolescents who received inadequate prenatal care [11]. They found that women who had no prenatal care had a nearly 8 -fold higher risk of preterm birth (odds ratio [OR], 7.9; 95\% confidence interval $[\mathrm{CI}], 6.1$ - 10.3), compared with those who attended $75 \%-100 \%$ of the recommended visits.

Notwithstanding this, most studies dealing with prenatal care or the lack there of have focused on the maternal aspect, investigating the determinants of late care, characteristics of women with late care, racial disparities and the utilization of available prenatal services [12-15]. Furthermore, studies investigating neonatal outcomes focus almost exclusively on prematurity, low birth weight, and neonatal mortality [16-18]. Only a few studies have looked beyond these parameters. For instance, a study by Herbst et al. assessed the effect of no prenatal care versus any care [19]. They found that those with no prenatal care were more likely to have infants with low birth weight, lower Apgar scores, respiratory distress syndrome, intraventricular hemorrhage, retinopathy of prematurity, broncho-pulmonary dysplasia, and death prior to discharge. These same findings were seen when they limited the analysis to low birth weight infants and after controlling for race and selected clinical variables. Limitations of this study were that it was hospital-based, the authors combined any degree of prenatal care into one group, there was no adjustment for gestational age, and there was limited adjustment for socio-demographic factors and birth weight.

The purpose of our population-based study was to examine neonatal morbidities associated with prenatal care, by comparing the differences in neonatal morbidities for neonates whose mother had no prenatal care with those whose mother had inadequate prenatal care, and with those receiving intermediate/adequate prenatal care. Our hypothesis is that neonates exposed to no prenatal care will have more severe morbidities compared with neonates with exposure to any prenatal care.

\section{MATERIALS AND METHODS}

A retrospective cohort study was performed using Arizona birth certificate data from 1994 to 1998, linked to data from Arizona's High Risk Perinatal Program/Newborn Intensive Care Program (NICP) in that same time frame. This Program assures care for the sickest neonates in the State of Arizona, and there is no income level for qualification. Criteria for enrollment include a Neonatal Intensive Care Unit stay of greater than 72 hours, and transport for neonatal intensive care or transport at the discretion of the neonatologist. Details of the program and the matching process have been previously published [20]. Women experiencing multiple births and women with missing data on the level of maternal prenatal care received were excluded from the study. We derived our exposure measure from the Kotelchuck Adequacy of Prenatal Care Utilization Index (APNCUI) [5] which uses data on the timing of initiation of care and number of visits to classify prenatal care into Inadequate (late care or few visits), Intermediate, Adequate and Adequate Plus (more visits than anticipated). For this study, a three-level Prenatal Care Scale was created. Records for which the value of the Kotelchuck Index was "Adequate Plus" and records with missing Kotelchuck Index scores were removed from the analysis. "Adequate Plus" was removed since it has been demonstrated that a significant number of women with high-risk pregnancies require additional visits and thus are a different population from that of our focus: women lacking prenatal care [21]. Group 1 was comprised of neonates exposed to no prenatal care (they are usually grouped in the index with the inadequate prenatal care group). Group 2 was comprised of those exposed to at least one prenatal visit but inadequate prenatal care according to the index. Group 3 was comprised of those exposed to intermediate/adequate prenatal care as defined by the index (see Figure 1). Intermediate and adequate care levels were combined because studies have shown that the differences in risk for complications are not markedly different in these two groups [21]. Demographic characteristics of the groups were compiled and comparisons were made using chi-square tests. Neonatal birth weight and estimated gestational age (based on the clinical estimate) were also similarly compared. The complications (neonatal morbidities) examined came

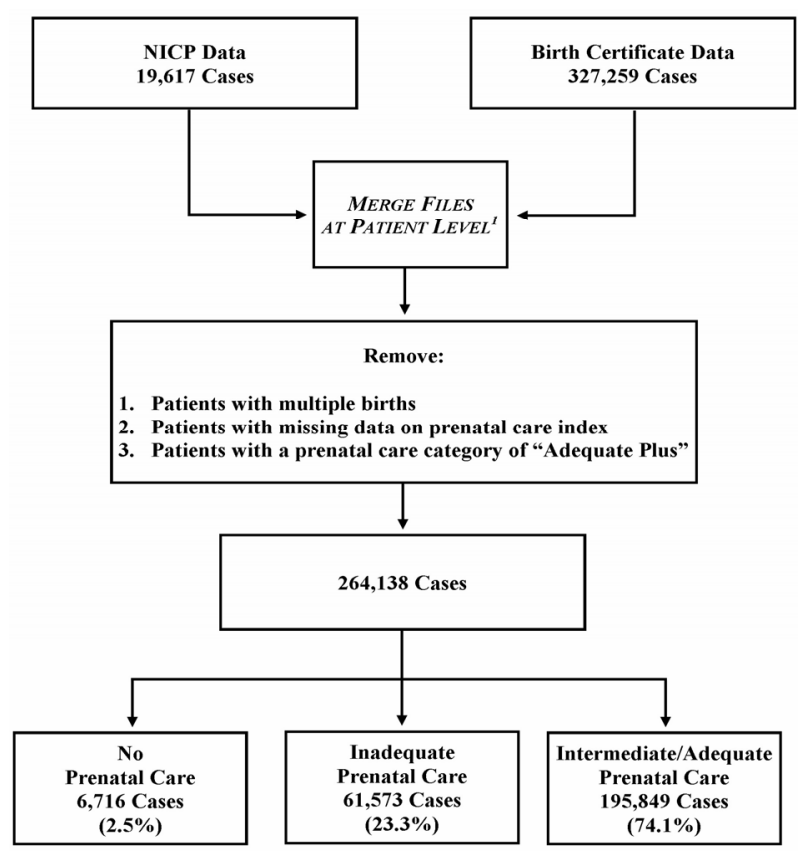

Figure 1. Study flow chart. 
from a form completed by the NICP program at discharge of the neonate. These forms were completed by medical personnel and submitted to the NICP program. A total of 22 different neonatal morbidities were included in the analyses (a list will be found in Table 4). The average number of complications was compared among Groups 1, 2 and 3 using Analysis of Variance (ANOVA). Rates of complications were calculated (per 10,000 births) and comparisons between groups were evaluated by calculating relative risks and $95 \%$ confidence intervals, with Group 3 used as the reference group.

Due to potential differences in socio-demographic factors, birth weight, and estimated gestational age, logistic regression analyses were conducted to adjust the results for these potential confounders. Unadjusted analysis was conducted (Model 1), followed by adjustment for socio-demographic factors found to be predictive of level of prenatal care (Model 2). The socio-demographic factors included in Model 2 were: ethnicity, mother's educational level, parity, mother's age, marital status, and insurance status. Next, the results were adjusted both for socio-demographics and birth weight (Model 3). Finally, the results were adjusted for socio-demographics, birth weight, and estimated gestational age (Model 4). Coding of the predictor variables is shown in Tables 2 and 3; all were coded as dummy variables. Significance was set at $\mathrm{p}$ less than or equal to 0.05 , and SPSS version 15.0 was used for statistical analysis. When comparing Group 1 to Group 3, the respective sample sizes of these two groups permitted us to detect an odds ratio of 6.1 or greater with $80 \%$ power at the $95 \%$ level of confidence. When comparing Group 2 to Group 3, the respective sample sizes of these two groups permitted us to detect an odds ratio of 2.7 or greater with $80 \%$ power at the $95 \%$ level of confidence. The study was reviewed by the Maricopa Integrated Health System Institutional Review Board (IRB) and was deemed exempt from IRB review, as no personal identifiers were included in the data set analyzed.

\section{RESULTS}

After all exclusions were applied, a total of 264,138 records were available from the linked NICP and Birth Certificate databases. A total of 6716 neonates were from pregnancies with no prenatal care (2.5\%), 61,573 had inadequate prenatal care (23.3\%), and 195,849 had intermediate/adequate prenatal care (74.1\%; Table 1). The mean number of diagnoses noted in the NICP discharge form was statistically significant $(p<0.001)$ with the highest number noted in the no prenatal group, followed by the inadequate group, and the smallest number in those with intermediate/adequate prenatal care (Table 1).
All socio-demographic characteristics that were examined showed significant associations with prenatal care (Table 2). Racial/ethnic background (African American, Native American and Hispanic, in particular those who were Mexico-born) was associated with higher rates of no prenatal care, as was being in a younger age group, having less than a high school education, being unmarried, being uninsured and being of higher parity. The risk of low birth weight was nearly six times higher in the no prenatal care group (Group 1) and three times higher in the inadequate prenatal care group (Group 2) compared to those in the intermediate/adequate care group (Group 3; Table 3). Especially notable was that the risk of having a birth weight less than 750 grams was 9.7 times higher in those in Group 1 as compared to those in Group 3. Compared to Group 3, similar elevated risks emerged for gestational age, prematurity, and degree of prematurity in Group 1, with intermediate levels of risk in those in Group 2.

In our univariate analysis of the neonatal morbidities, a pattern of highest risk for morbidity in the group with no prenatal care, and intermediate risk for morbidity in the group with inadequate prenatal care, emerged (Table 4). The only exception to this pattern was chromosomal anomalies. A pattern in which the relative risks were statistically significantly increased for both the Group 1 and Group 2 was observed for neurological conditions of periventricular leukomalacia, severe intracranial hemorrhage (grade III or IV); all respiratory conditions, all infectious complications except proven bacterial sepsis, dysmorphic features on exam, apnea bradycardia and polycythemia. Among conditions for which Group 1 had an especially high relative risk (5 times elevated risk or more) were: periventricular leukomalacia, severe intracranial hemorrhage, broncho-pulmonary dysplasia, proven viral sepsis, TORCH infection, dysmorphic features, apnea bradycardia and proven necrotizing enterocolitis.

Since the groups differed in socio-demographic characteristics and in the risk of low birth weight and prematurity, multivariable logistic regression was conducted (Table 5). When we controlled for the socio-demographic characteristics, the pattern of risks was essentially unchanged, although in general the risks were slightly attenuated (Model 2). After controlling for birth

Table 1. Subjects with no prenatal care, inadequate and intermediate/adequate prenatal care and mean number of diagnoses.

\begin{tabular}{cccc}
\hline Group & $\mathrm{N}$ & $\%$ & $\begin{array}{c}\text { Mean number of diagnoses } \\
\text { noted on discharge form }\end{array}$ \\
\hline No visits & 6716 & 2.5 & $0.151 \pm 0.612$ \\
Inadequate & 61,573 & 23.3 & $0.062 \pm 0.374$ \\
Intermediate/Adequate & 195,849 & 74.1 & $0.036 \pm 0.294$ \\
\hline
\end{tabular}

p $<0.001$ by ANOVA; ${ }^{\dagger} \pm$ Standard deviation. 
Table 2. Demographic characteristics by level of prenatal care*

\begin{tabular}{|c|c|c|c|c|c|c|}
\hline \multirow{2}{*}{ Characteristic } & \multicolumn{2}{|c|}{ No visits } & \multicolumn{2}{|c|}{ Inadequate } & \multicolumn{2}{|c|}{ Interm./Adequate } \\
\hline & $\mathrm{N}$ & $\%$ & $\mathrm{~N}$ & $\%$ & $\mathrm{~N}$ & $\%$ \\
\hline \multicolumn{7}{|l|}{ Age (years) } \\
\hline$<18$ & 616 & 9.2 & 5656 & 9.2 & 8661 & 4.4 \\
\hline $18-24$ & 2944 & 43.8 & 28,817 & 46.8 & 66,722 & 34.1 \\
\hline $25-29$ & 1557 & 23.2 & 14,042 & 22.8 & 55,069 & 28.1 \\
\hline $30-34$ & 990 & 14.7 & 8244 & 13.4 & 42,995 & 22.0 \\
\hline $35+$ & 607 & 9.0 & 4813 & 7.8 & 22,397 & 11.4 \\
\hline \multicolumn{7}{|l|}{ Education (years) } \\
\hline$<12$ & 4113 & 65.4 & 29,930 & 50.4 & 45,450 & 23.6 \\
\hline 12 & 1601 & 25.5 & 18,892 & 31.8 & 61,989 & 32.2 \\
\hline$>12$ & 576 & 9.2 & 10,581 & 17.8 & 85,330 & 44.3 \\
\hline \multicolumn{7}{|l|}{ Marital status } \\
\hline Unmarried & 4727 & 70.5 & 36,101 & 58.7 & 63,939 & 32.7 \\
\hline Married & 1979 & 29.5 & 25,450 & 41.3 & 131,872 & 67.3 \\
\hline \multicolumn{7}{|l|}{ Insurance } \\
\hline Medicaid & 3601 & 56.2 & 41,416 & 71.1 & 74,051 & 38.9 \\
\hline Private & 639 & 10.0 & 11,610 & 19.9 & 106,578 & 55.9 \\
\hline Self/Unknown & 2168 & 33.8 & 5261 & 9.0 & 9871 & 5.2 \\
\hline \multicolumn{7}{|l|}{ Parity } \\
\hline 0 & 1838 & 27.6 & 21,405 & 34.8 & 78,437 & 40.1 \\
\hline 1 & 1645 & 24.7 & 17,059 & 27.8 & 61,165 & 31.3 \\
\hline $2+$ & 3187 & 47.8 & 23,002 & 37.4 & 56,098 & 28.7 \\
\hline \multicolumn{7}{|l|}{ Race/Ethnicity } \\
\hline Asian & 64 & 1.0 & 824 & 1.3 & 4163 & 2.1 \\
\hline African-American & 330 & 4.9 & 2509 & 4.1 & 7206 & 3.7 \\
\hline Caucasian & 1653 & 24.8 & 19,380 & 31.6 & 112,266 & 57.5 \\
\hline Native American & 638 & 9.6 & 7273 & 11.9 & 12,247 & 6.3 \\
\hline US born Hispanic & 1112 & 16.7 & 10,606 & 17.3 & 30,180 & 15.5 \\
\hline Mexico born Hispanic & 2871 & 43.1 & 20,662 & 33.7 & 29,229 & 15.0 \\
\hline
\end{tabular}

*All differences between groups significant $(\mathrm{p}<0.05)$.

weight, the number of morbidities that remained significantly associated with level of prenatal care was reduced (Model 3), and was reduced further after adjustment for both gestational age and birth weight (Model 4). However, even after the Model 4 adjustments were performed, when compared to the intermediate/adequate group, members of the no visit group continued to show increased risk for meconium aspiration, odds ratio (OR)
2.15 and confidence interval $(\mathrm{CI}), 1.39$ - 3.33; suspected sepsis, OR 1.30 and CI 1.13 - 1.49; proven viral sepsis, OR 2.23 and CI 1.24 to 4.00; and dysmorphic features, OR 1.99 and CI 1.07 - 3.70. In comparing the inadequate prenatal group to the intermediate/adequate group, only transient tachypnea of the newborn (OR 1.29; CI 1.09 1.52) and suspected sepsis (OR 1.19; CI 1.10 - 1.28) were significant after adjustment using Model 4. 
Table 3. Birth weight and estimated gestational age by level of prenatal care*.

\begin{tabular}{|c|c|c|c|c|c|c|}
\hline \multirow{2}{*}{ Characteristic } & \multicolumn{2}{|c|}{ No visits } & \multicolumn{2}{|c|}{ Inadequate } & \multicolumn{2}{|c|}{ Interm./Adequate } \\
\hline & $\mathrm{N}$ & $\%^{\dagger}$ & $\mathrm{N}$ & $\%$ & $\mathrm{~N}$ & $\%$ \\
\hline \multicolumn{7}{|c|}{ Birth weight (grams) } \\
\hline$<750$ & 74 & 1.1 & 114 & 0.2 & 229 & 0.1 \\
\hline $750-1000$ & 60 & 0.9 & 96 & 0.2 & 142 & 0.1 \\
\hline $1001-1500$ & 113 & 1.7 & 249 & 0.4 & 296 & 0.1 \\
\hline $1501-2500$ & 776 & 11.6 & 3053 & 5.0 & 4589 & 2.3 \\
\hline$>2500$ & 5660 & 84.7 & 57,979 & 94.3 & 195,765 & 97.4 \\
\hline \multicolumn{7}{|c|}{ Estimated gestational age (weeks) } \\
\hline $20-27$ & 152 & 2.3 & 219 & 0.4 & 335 & 0.2 \\
\hline $28-31$ & 165 & 2.5 & 368 & 0.6 & 313 & 0.2 \\
\hline $32-36$ & 1086 & 16.2 & 4243 & 7.6 & 4173 & 2.1 \\
\hline $37+$ & 5305 & 79.1 & 56,730 & 92.2 & 191,013 & 97.5 \\
\hline
\end{tabular}

*All differences between groups significant $(\mathrm{p}<0.05) .{ }^{\dagger}$ Percentages are the percentage of the cohort with the birth weight or gestational age in that category.

\section{DISCUSSION}

Using linked data from Arizona Birth Certificates and from Arizona's High Risk Perinatal Program/Newborn Intensive Care Program, we assessed how the level of prenatal care received affected neonatal morbidities. As we hypothesized, we found a greater degree of morbidity among neonates with no prenatal care compared to those with intermediate/adequate prenatal care. This included the number of diagnoses at discharge and a higher risk of clinically significant diagnoses such as periventricular leuckomalacia, intraventricular hemorrhage, bronchopulmonary dysplasia, respiratory distress, infectious complications and necrotizing fasciitis. Those with no prenatal care had smaller and more premature neonates, so it was not surprising to find that on adjustment in multivariable analysis many of these associations were no longer significant.

Our study is limited primarily by the data source used. Since these were administrative data, we were unable to verify the diagnoses noted at discharge; however we note that since the program diagnosis form is completed after neonatal hospitalization, that this is likely to be superior to any neonatal diagnoses noted on a birth certificate which is completed immediately after birth.

Another potential source of bias is that those with no prenatal care might be more likely to have a diagnosis, as they might be more likely to have been admitted to a Neonatal Intensive Care Unit by virtue of not having prenatal care. Given that a three-day stay in an intensive care unit is required for admission to the program and is the most common reason for enrollment, we believe this to be a minimal source of bias [20].
There is also the possibility of inaccuracy in measurement of the exposure variable. One study of birth certificates, maternal questionnaires and medical records in the recording of prenatal care did find some discrepancies [22].

Another limitation is that these data are from 19941998, which may limit somewhat the generalizability of our results. However, we do not believe that this alters our central findings or their clinical meaning. It is true that GBS screening, administration of antenatal steroids, progesterone therapy in patients with a history of preterm labor, and other management methods did not become important until after this period. However, patients in the current "era" of obstetrical care who do not receive prenatal care would not have received these measures anyway, and thus would be similar to those seen in the study time frame. This suggests that, had this study been conducted with more recent data, the "morbidity gap" between no-prenatal care patients and prenatal care patients would have been even larger.

Despite these limitations, this large dataset allowed us to examine neonatal morbidities by level of prenatal care and extend prior studies which have either focused on risk factors for no prenatal care, or examined limited neonatal outcomes such as low birth weight and preterm birth. We were not surprised that few associations, especially those related to prematurity or low birth weight, remained significant after adjustment. This is also compatible with a study which found no differences in neonatal mortality after adjusting for these same variables [6]. This is probably because prematurity is in the causal pathway with most of these morbidities. We note that 
Table 4. Associations of level of prenatal care with neonatal morbidity.

\begin{tabular}{|c|c|c|c|c|c|c|c|c|}
\hline \multirow{2}{*}{ Condition } & \multicolumn{3}{|c|}{ No Visits } & \multicolumn{3}{|c|}{ Inadequate } & \multicolumn{2}{|c|}{ Interm./Adequate } \\
\hline & $\mathrm{N}$ & Rate/10,000 & $\mathrm{RR}\left(95 \% \mathrm{CI}^{\ddagger}\right)$ & $\mathrm{N}$ & Rate $/ 10,000$ & $\mathrm{RR}\left(95 \% \mathrm{CI}^{\ddagger}\right)$ & $\mathrm{N}$ & Rate $/ 10,000$ \\
\hline \multicolumn{9}{|l|}{ Neurologic } \\
\hline Abnormal neurological exam & 4 & 5.95 & $2.01(0.73,5.53)$ & 24 & 3.9 & $1.31(0.82,2.12)$ & 58 & 2.96 \\
\hline Periventricular leukomalacia & 7 & 10.42 & $10.74(4.52,25.55)$ & 15 & 2.44 & $2.51(1.28,4.94)$ & 19 & 0.97 \\
\hline \multicolumn{9}{|l|}{ Intraventricular hemorrhage } \\
\hline Any grade & 10 & 14.89 & $4.63(2.38,9.02)$ & 27 & 4.39 & $1.36(0.87,2.14)$ & 63 & 3.22 \\
\hline Grade III/IV & 11 & 16.37 & $8.67(4.42,16.99)$ & 23 & 37.35 & $1.97(1.18,3.33)$ & 37 & 1.88 \\
\hline Hypoxic encephalopathy & 1 & 1.49 & $1.27(0.17,9.39)$ & 9 & 1.46 & $1.24(0.58,2.69)$ & 23 & 1.17 \\
\hline Seizures & 19 & 28.29 & $3.69(2.29,5.95)$ & 54 & 8.77 & $1.15(0.84,1.56)$ & 150 & 7.66 \\
\hline \multicolumn{9}{|l|}{ Respiratory } \\
\hline Meconium aspiration & 27 & 40.20 & $2.62(1.77,3.88)$ & 125 & 20.30 & $1.32(1.07,1.63)$ & 301 & 15.36 \\
\hline Broncho-pulmonary dysplasia & 27 & 40.20 & $10.36(6.68,16.06)$ & 38 & 6.17 & $1.59(1.08,2.35)$ & 76 & 3.88 \\
\hline Respiratory distress & 246 & 366.29 & $4.88(4.27,5.57)$ & 824 & 133.82 & $1.78(1.64,1.94)$ & 1470 & 75.06 \\
\hline Pneumothorax or mediastinum & 14 & 20.85 & $2.14(1.24,3.68)$ & 88 & 14.29 & $1.47(1.14,1.87)$ & 191 & 9.75 \\
\hline Transient tachypnea & 48 & 71.47 & $2.61(1.94,3.5)$ & 270 & 43.85 & $1.6(1.38,1.85)$ & 537 & 27.41 \\
\hline \multicolumn{9}{|l|}{ Infectious } \\
\hline Pneumonia & 30 & 44.67 & $2.26(1.56,3.27)$ & 168 & 27.28 & $1.38(1.15,1.65)$ & 387 & 19.76 \\
\hline Suspected sepsis & 397 & 591.12 & $4.05(3.65,4.49)$ & 1644 & 267.00 & $1.83(1.72,1.94)$ & 2857 & 145.88 \\
\hline Proven bacterial sepsis & 14 & 20.85 & $2.85(1.64,4.91)$ & 56 & 9.09 & $1.23(0.91,1.68)$ & 144 & 7.35 \\
\hline Proven viral sepsis & 28 & 41.69 & $15.7(9.92,24.84)$ & 36 & 5.85 & $2.2(1.44,3.37)$ & 52 & 2.66 \\
\hline TORCH infection & 7 & 10.42 & $11.34(4.74,27.14)$ & 14 & 2.27 & $2.47(1.23,4.97)$ & 18 & 0.92 \\
\hline \multicolumn{9}{|l|}{ Anomalies } \\
\hline Chromosomal & 2 & 2.98 & $1.72(0.41,7.14)$ & 25 & 4.06 & $2.34(1.39,3.92)$ & 34 & 1.74 \\
\hline Dysmorphic features & 17 & 25.31 & $5.57(3.32,9.35)$ & 47 & 7.63 & $1.68(1.18,2.39)$ & 89 & 4.54 \\
\hline Congenital defect & 6 & 8.93 & $2.33(1.01,5.36)$ & 31 & 5.03 & $1.31(0.87,2)$ & 75 & 3.83 \\
\hline \multicolumn{9}{|l|}{ Other } \\
\hline Apnea bradycardia & 77 & 114.65 & $8.23(6.39,10.58)$ & 193 & 31.34 & $2.24(1.87,2.7)$ & 273 & 13.94 \\
\hline Polycythemia & 8 & 11.91 & $4.24(2.02,8.9)$ & 38 & 6.17 & $2.19(1.45,3.32)$ & 55 & 2.80 \\
\hline Proven necrotizing enterocolitis & 3 & 4.47 & $7.95(2.22,28.5)$ & 8 & 1.30 & $2.31(0.93,5.75)$ & 11 & 0.56 \\
\hline
\end{tabular}

${ }^{*}$ Reference group. ${ }^{\dagger} \mathrm{RR}=$ Relative Risk. ${ }^{\ddagger} \mathrm{CI}=$ Confidence Interval.

our findings contrast with those of Herbst et al. who found persistently statistically significant increased risk of severe morbidity in those with no prenatal care; however they did not control for gestational age and only adjusted for birth weight incompletely by performing a sub-analysis in those of low birth weight [19]. Our view is supported by the associations which remained significant after adjustment: meconium aspiration, viral sepsis, and dysmorphic features. Perhaps it is the characteristics of the women who get no prenatal care that leads to the preterm birth and not the lack of prenatal care [23].

As they are derived from population-based data, our results are most generalizable to other areas of the United States, especially those in the South and West. We make note that during the time period of this data set, as a result of welfare reform, prenatal care became unfunded for 
Table 5. Odds ratios for neonatal outcomes by level of prenatal care.

\begin{tabular}{|c|c|c|c|c|c|c|c|c|}
\hline \multirow{3}{*}{ Outcome Variable } & \multicolumn{2}{|c|}{ Model $1^{*}$} & \multicolumn{2}{|c|}{ Model $2^{*}$} & \multicolumn{2}{|c|}{ Model $3^{*}$} & \multicolumn{2}{|c|}{ Model $4^{*}$} \\
\hline & Unad & usted & Demo & raphics & Demograp & $\begin{array}{l}\text { ics + Birth } \\
\text { ght }\end{array}$ & $\begin{array}{r}\text { Demograp } \\
\text { Weight }\end{array}$ & $\begin{array}{l}\text { ics + Birth } \\
+\mathrm{EGA}^{\dagger}\end{array}$ \\
\hline & No Visits & Inadequate & No Visits & Inadequate & No Visits & Inadequate & No Visits & Inadequate \\
\hline Periventricular leukomalacia & $10.75^{\ddagger}$ & $2.51^{\ddagger}$ & $12.03^{\ddagger}$ & $2.63^{\ddagger}$ & $3.12^{\ddagger}$ & $2.16^{\ddagger}$ & 1.75 & 1.47 \\
\hline Grade III/IV intraventricular hemorrhage & $8.68^{\ddagger}$ & $1.98^{\ddagger}$ & $11.87^{\ddagger}$ & $2.45^{\ddagger}$ & $2.82^{\ddagger}$ & $1.84^{\ddagger}$ & 1.81 & 1.46 \\
\hline Any grade intraventricular hemorrhage & $4.63^{\ddagger}$ & 1.36 & $3.46^{\ddagger}$ & 1.18 & 0.89 & 0.99 & 0.49 & 0.63 \\
\hline Seizures & $3.7^{\ddagger}$ & 1.15 & $3.64^{\ddagger}$ & 1.26 & $2.2^{\ddagger}$ & 1.15 & 1.74 & 1.06 \\
\hline Meconium aspiration & $2.62^{\ddagger}$ & $1.32^{\ddagger}$ & $2.47^{\ddagger}$ & 1.21 & $2.25^{\ddagger}$ & 1.21 & $2.15^{\ddagger}$ & 1.17 \\
\hline Broncho-pulmonary dysplasia & $10.4^{\ddagger}$ & $1.59^{\ddagger}$ & $7.44^{\ddagger}$ & 1.25 & $1.89^{\ddagger}$ & 0.95 & 0.96 & 0.66 \\
\hline Respiratory distress & $5.03^{\ddagger}$ & $1.79^{\ddagger}$ & $4.59^{\ddagger}$ & $1.69^{\ddagger}$ & $2.02^{\ddagger}$ & $1.47^{\ddagger}$ & 0.90 & 0.95 \\
\hline Pneumothorax & $2.14^{\ddagger}$ & $1.47^{\ddagger}$ & $1.95^{\ddagger}$ & $1.42^{\ddagger}$ & 1.47 & $1.36^{\ddagger}$ & 1.23 & 1.28 \\
\hline Transient tachypnea & $2.62^{\ddagger}$ & $1.6^{\ddagger}$ & $2.86^{\ddagger}$ & $1.7^{\ddagger}$ & $2.09^{\ddagger}$ & $1.62^{\ddagger}$ & 1.36 & $1.29^{\ddagger}$ \\
\hline Pneumonia & $2.27^{\ddagger}$ & $1.38^{\ddagger}$ & $2.31^{\ddagger}$ & $1.32^{\ddagger}$ & 1.51 & $1.25^{\ddagger}$ & 1.20 & 1.15 \\
\hline Suspected sepsis & $4.24^{\ddagger}$ & $1.85^{\ddagger}$ & $3.81^{\ddagger}$ & $1.7^{\ddagger}$ & $2.28^{\ddagger}$ & $1.56^{\ddagger}$ & $1.30^{\ddagger}$ & $1.19^{\ddagger}$ \\
\hline Proven bacterial sepsis & $2.84^{\ddagger}$ & 1.24 & $2.16^{\ddagger}$ & 1.04 & 1.09 & 0.93 & 0.75 & 0.80 \\
\hline Proven viral sepsis & $15.76^{\ddagger}$ & $2.2^{\ddagger}$ & $8.61^{\ddagger}$ & 1.55 & $3.35^{\ddagger}$ & 1.37 & $2.23^{\ddagger}$ & 1.18 \\
\hline TORCH infection & $11.35^{\ddagger}$ & $2.47^{\ddagger}$ & $6.33^{\ddagger}$ & 1.7 & $3.76^{\ddagger}$ & 1.59 & 2.83 & 1.3 \\
\hline Chromosomal syndrome & 1.72 & $2.34^{\ddagger}$ & 1.34 & $1.99^{\ddagger}$ & 0.91 & $1.8^{\ddagger}$ & 0.89 & 1.73 \\
\hline Congenital defect & $2.33^{\ddagger}$ & 1.32 & 2.22 & 1.28 & 1.33 & 1.19 & 0.96 & 0.96 \\
\hline Dysmorphic features & $5.58^{\ddagger}$ & $1.68^{\ddagger}$ & $3.84^{\ddagger}$ & $1.48^{\ddagger}$ & $2.6^{\ddagger}$ & 1.41 & $1.99^{\ddagger}$ & 1.20 \\
\hline Apnea bradycardia & $8.31^{\ddagger}$ & $2.25^{\ddagger}$ & $6.58^{\ddagger}$ & $1.98^{\ddagger}$ & $2.83^{\ddagger}$ & $1.73^{\ddagger}$ & 1.28 & 1.06 \\
\hline Polycythemia & $4.25^{\ddagger}$ & $2.2^{\ddagger}$ & $3.01^{\ddagger}$ & $1.8^{\ddagger}$ & 1.99 & $1.69^{\ddagger}$ & 1.55 & 1.48 \\
\hline Proven necrotizing enterocolitis & $7.96^{\ddagger}$ & 2.31 & $6.23^{\ddagger}$ & 2.1 & 1.85 & 1.76 & 0.96 & 1.01 \\
\hline
\end{tabular}

* Reference group was those with intermediate/adequate prenatal care. Coding of adjustment variables was that as shown in Tables 2 and 3 ; all variables from those tables were included and all were dummy-coded. ${ }^{\dagger}$ EGA $=$ Estimated Gestational Age. ${ }^{\ddagger}$ Statistically significant $(\mathrm{p} \leq 0.05)$.

non-citizens in our State. Indeed the group most likely to have no visits was Hispanics who were born in Mexico. This group has been shown to have less low birth weight, growth restriction and prematurity than might be expected - the Latino "paradox" [24-26] — so some caution should apply before generalizing these results. However, being population-based, this study is not subject to the biases inherent in hospital-based studies.

Implications of our study for clinicians are that the "drop in" patient represents a patient at elevated risk for neonatal morbidities beyond that of a low birth weight or premature infant. As a consequence, should they not deliver after first presenting to a hospital, special effort should be made to create linkages between the hospital and the clinic to capture the benefits that might result from prenatal care. The implications of this study for policy makers are that there is still a substantial amount of the population that do not avail themselves of the preventive services that prenatal care represents. Moreover, since prenatal care has been one of the services approaching universal coverage, this means that even in these conditions there are those who will not take advantage of these services [7,27]. Understanding this as healthcare coverage improves with health care reform will have broader implications as the Patient Protection and Affordable Care Act begins to be implemented in the 
upcoming years [28].

\section{ACKNOWLEDGEMENTS}

Funded in part by CMS Award \# 25-P-90947/9-02.

Presented at the 77th Annual Meeting of the Pacific Coast Obstetrical and Gynecological Society, Kohala Coast, Hawaii, October 2010.

\section{REFERENCES}

[1] Hogan, M.C., Foreman, K.J., Naghavi, M., Ahn, S.Y., Wang, M., Makela, S.M., Lopez, A.D., Lozano, R. and Murray, C.J. (2010) Maternal mortality for 181 countries, 1980-2008: A systematic analysis of progress towards Millennium Development Goal 5. Lancet, 375, 1609-1623. doi:10.1016/S0140-6736(10)60518-1

[2] Moccia, P. and Anthony, D., Eds. (2009) The state of the world's children. United Nations Children's Fund (UNICEF), New York.

[3] Leveno, K.J., Cunningham, F.G., Roark, M.L., Nelson, S.D. and Williams, M.L. (1985) Prenatal care and the low birth weight infant. Obstetrics \& Gynecology, 66, 599605.

[4] Kessner, D.M., Singer, J. and Kalk, C.W. (1973) Infant death: An analysis by maternal risk and health care. In: Contrasts in Health Status, 1, Institute of Medicine and National Academy of Sciences, Washington DC.

[5] Kotelchuck, M. (1994) An evaluation of the Kessner adequacy of prenatal care index and a proposed adequacy of prenatal care utilization index. American Journal of Public Health, 84, 1414-1420. doi:10.2105/AJPH.84.9.1414

[6] Alexander, G.R. and Cornely, D.A. (1987) Prenatal care utilization: Its measurement and relationship to pregnancy outcome. American Journal of Preventive Medicine, 3, 243253.

[7] Raatikainen, K., Heiskanen, N. and Heinonen, S. (2007) Under-attending free antenatal care is associated with adverse pregnancy outcomes. BMC Public Health, 7, 268. doi:10.1186/1471-2458-7-268

[8] Williams, J.W. (1915) The limitations and possibilities of prenatal care. Based on the study of 705 fetal deaths occurring in 10,000 consecutive admissions to the obstetrical department of the Johns Hopkins Hospital. The Journal of the American Medical Association, 64, 95. doi:10.1001/jama.1915.02570280001001

[9] Eastman, N.J. (1947) Prematurity from the viewpoint of the obstetrician. American Practitioner and Digest of Treatment, 1, 343-352.

[10] Tokuhata, G.K., Digon, E. and Mann, L. (1973) Prenatal care and obstetric abnormalities. Experiences of 185,000 Pennsylvania births. Journal of Chronic Diseases, 26, 163 185. doi:10.1016/0021-9681(73)90088-X

[11] Debiec, K.E., Paul, K.J., Mitchell, C.M. and Hitti, J.E. (2010) Inadequate prenatal care and risk of preterm delivery among adolescents: A retrospective study over 10 years. American Journal of Obstetrics \& Gynecology, 203, 122.e1-e6.
[12] McCaw-Binns, A., La Grenade, J. and Ashley, D. (1995) Under-users of antenatal care: A comparison of non-attenders and late attenders for antenatal care, with early attenders. Social Science \& Medicine, 40, 1003-1012. doi:10.1016/0277-9536(94)00175-S

[13] Blondel, B. and Marshall, B. (1998) Poor antenatal care in 20 French districts: Risk factors and pregnancy outcome. Journal of Epidemiology \& Community Health, 52, 501-506. doi:10.1136/jech.52.8.501

[14] Delvaux, T., Buekens, P., Godin, I. and Boutsen, M. (2001) Barriers to prenatal care in Europe. American Journal of Preventive Medicine, 21, 52-59. doi:10.1016/S0749-3797(01)00315-4

[15] Kupek, E., Petrou, S., Vause, S. and Maresh, M. (2002) Clinical, provider and sociodemographic predictors of late initiation of antenatal care in England and Wales. British Journal of Obstetrics and Gynaecology, 109, 265273. doi:10.1111/j.1471-0528.2002.00524.x

[16] Gissler, M. and Hemminki, E. (1994) Amount of antenatal care and infant outcome. European Journal of Obstetrics \& Gynecology and Reproductive Biology, 56, 9-14. doi:10.1016/0028-2243(94)90146-5

[17] Vintzileos, A.M., Ananth, C.V., Smulian, J.C., Scorza, W.E. and Knuppel, R.A. (2002) The impact of prenatal care on neonatal deaths in the presence and absence of antenatal high-risk conditions. American Journal of $\mathrm{Ob}$ stetrics and Gynecology, 186, 1011-1016. doi:10.1067/mob.2002.122446

[18] Chen, X.K., Wen, S.W., Yang, Q. and Walker, M.C. (2007) Adequacy of prenatal care and neonatal mortality in infants born to mothers with and without antenatal highrisk conditions. Australian and New Zealand Journal of Obstetrics and Gynaecology, 47, 122-127. doi:10.1111/j.1479-828X.2007.00697.x

[19] Herbst, M.A., Mercer, B.M., Beazley, D., Meyer, N. and Carr, T. (2003) Relationship of prenatal care and perinatal morbidity in low-birth-weight infants. American Journal of Obstetrics and Gynecology, 189, 930-933. doi:10.1067/S0002-9378(03)01055-X

[20] Moore, P.D., Bay, R.C., Balcazar, H., Coonrod, D.V., Brady, J. and Russ, R. (2005) Use of home visit and developmental clinic services by high risk Mexican-American and white non-Hispanic infants. Maternal and Child Health Journal, 9, 35-47. doi:10.1007/s10995-005-2449-1

[21] Kotelchuck, M. (1994) The adequacy of prenatal care utilization index: Its US distribution and association with low birthweight. American Journal of Public Health, 84, 1486-1489. doi:10.2105/AJPH.84.9.1486

[22] Forrest, J.D. and Singh, S. (1987) Timing of prenatal care in the United States: How accurate are our measurements? Health Services Research, 22, 235-253.

[23] Fiscella, K. (1995) Does prenatal care improve birth outcomes? A critical review. Obstetrics \& Gynecology, 85, 468-479. doi:10.1016/0029-7844(94)00408-6

[24] Markides, K.S. and Coreil, J. (1986) The health of hispanics in the southwestern United States: An epidemiologic paradox. Public Health Reports, 101, 253-265.

[25] Chung, J.H., Boscardin, W.J., Garite, T.J., Lagrew, D.C. 
and Porto, M. (2003) Ethnic differences in birth weight by gestational age: At least a partial explanation for the Hispanic epidemiologic paradox? American Journal of Obstetrics and Gynecology, 189, 1058-1062. doi:10.1067/S0002-9378(03)00848-2

[26] Coonrod, D.V., Bay, R.C. and Balcazar, H. (2004) Ethnicity, acculturation and obstetric outcomes. Different risk factor profiles in low- and high-acculturation Hispanics and in white non-Hispanics. The Journal of Reproductive
Medicine, 49, 17-22.

[27] Nothnagle, M., Marchi, K., Egerter, S. and Braveman, P. (2000) Risk factors for late or no prenatal care following Medicaid expansions in California. Maternal and Child Health Journal, 4, 251-259. doi:10.1023/A:1026647722295

[28] Health Care and Education Reconciliation Act of 2010 (2010) Public Law 111-152, 124 Stat. 1029-1083. 